\title{
Phytomonas iron superoxide dismutase: a possible molecular marker
}

\author{
Clotilde Marín a , Ana B. Hitos a , Isabel Rodríguez-González ${ }^{\text {a }}$, Michel Dollet ${ }^{\text {b }}$, \\ Manuel Sánchez-Moreno ${ }^{\text {a,* }}$ \\ a Instituto de Biotecnología, Facultad de Ciencias, Universidad de Granada, C/Severo Ochoa s/n, 18071 Granada, Spain \\ ${ }^{\mathrm{b}}$ CIRAD, TA 30/G, Campus International de Baillarguet, 34398 Montpellier Cedex 5, France
}

Received 13 January 2004; received in revised form 4 March 2004; accepted 5 March 2004

First published online 18 March 2004

\begin{abstract}
We have isolated and biochemically characterized two iron superoxide dismutases activities (SODI and SODII) from a plant trypanosomatid isolated from Euphorbia characias. The isoenzyme FeSODII has immunogenic capacity, and the positivity of the anti-SODII serum persists to a dilution of $1 / 40,000$, by Western blot. In addition, Western blot has been used to test the positivity of the anti-SODII serum against antigen fractions (SOD) from 17 isolates belonging to the family Trypanosomatidae and for which we had previously determined the isoenzymatic profile. The reaction proved positive only with those plant isolates considered to belong to the genus Phytomonas, whereas there was no reaction of the anti-SODII serum, against the antigen fractions from the species Trypanosoma cruzi, Leishmania donovani, Herpetomonas samuelpessoai, Herpetomonas davidi, Crithidia luciliae and Leptomonas collosoma. FeSODII is located mainly over the entire surface of the parasite, as well as in the nucleus, glycosomes and membranes. The above makes FeSODII promising as a molecular tool for diagnosis and identification, and as a potential chemotherapeutic target for designing drugs aimed at controlling not only of the diseases caused by Phytomonas species, but also for the great metabolic similarity to other trypanosomatids of animals and humans, it may be possible for these results to be extrapolated. Moreover, the sequencing of the amino-terminal end of the FeSODII enables the design of primers that in the near future will make it possible to sequence the gene of this isoenzyme.
\end{abstract}

(c) 2004 Federation of European Microbiological Societies. Published by Elsevier B.V. All rights reserved.

Keywords: Superoxide dismutase; Immunogenicity; Molecular tool; Phytomonas; Trypanosomatids

\section{Introduction}

Plants can be parasitized by members of the family Trypanosomatidae, more particularly by species of the genus Phytomonas [1]. These trypanosomatids provoke wilt in crops in Latin America, the Caribbean, Africa, Europe, and India (coconut, oil palm, coffee, Alpinia purpurata, Euphorbes, and Asclepiades). Also, Phytomonas have been isolated from fruits such as tomatoes, tangerines and cherimoya [1,2]. In crops such as coffee, coconut and oil palm, Phytomonas infection can have devastating consequences [1]. The traditional taxonomic

\footnotetext{
${ }^{*}$ Corresponding author. Tel.: +34-958-242369; fax: +34-958-243174

E-mail address: msanchem@ugr.es (M. Sánchez-Moreno).
}

criteria such as morphology, host, and geographical origin are not useful because the same organism can harbour different Phytomonas species, and also trypanosomatids from other genus (Crithidia and Leptomonas) [3], making it necessary to search for new methods of correct classification.

For many intracellular parasites and bacterial pathogens, superoxide dismutase (SOD), a metalloenzyme present in all oxygen-breathing organisms, constitutes the first line of defence against oxidative damage caused by catalysing the dismutation of the superoxide radical to molecular oxygen and hydrogen peroxide [4]. Three classes of SODs have been identified, depending on the metal cofactor - iron (FeSOD), manganese (MnSOD) and copper-zinc (Cu/ZnSOD) - which also differ in their location: cytosol, cell organelles, and even 
cell excretions. Thus, the $\mathrm{Cu} / \mathrm{ZnSODs}$ appear primarily in the cytosol of eukaryotic cells; the MnSODs in the mitochondrial matrix; and FeSODs in the cytosol of plant cells as well as in some free-living protozoa and protozoan parasites. The SOD type can be identified by its susceptibility to inhibition by hydrogen peroxide and sodium cyanide [5].

SODs from protozoan parasites are considered factors of virulence that protect the parasites from attack of the host cells by the action both of oxidant and anti-inflammatory agents [6], and can even confer immunological capacities [7]. In general, all the parasitic protozoa studied to date have only FeSOD $[4,6,8,9]$.

Ever since it was discovered that SODs from parasitic protozoa were FeSODs and that they differed from those of the vertebrate host not only structurally but also in the inhibitor, SODs have been proposed as potential chemotherapeutical targets [8]. Also, in some parasitic protozoa, it has been demonstrated that some proteins involved in the oxidative attack (SODs) are highly immunogenic, raising the possibility of using them in the diagnosis of the disease [7].

Recently, we have purified two iron superoxide dismutases (SODI and SODII) from a plant trypanosomatid isolated from Euphorbia characias and characterized by several biochemical properties [10]. The present study was aimed at analysing the potential immunological properties, as well as the sequencing of the SODs of Phytomonas, in order to make a molecular tool that would enable us to identify and diagnose these trypanosomatids with certainty. This could also open new paths not only of fighting diseases in plants but also of extrapolating these results to human trypanosomiases for the great similarity between pathogens.

\section{Materials and methods}

\subsection{Parasites and culture}

Phytomonas isolated from latex vessels of E. characias were grown in axenic Grace's medium (Gibco) supplemented with $10 \%$ heat inactivated foetal bovine serum at $28{ }^{\circ} \mathrm{C}$ in Falcon flasks. Cells were collected at the late logarithmic-phase of growth by centrifugation $(1500 \mathrm{~g}$ for $5 \mathrm{~min}$ at room temperature). The pellet of cells was washed twice and resuspended in ice-cold STE buffer (0.25 M sucrose, $25 \mathrm{mM}$ Tris- $\mathrm{HCl}, 1 \mathrm{mM}$ EDTA, $\mathrm{pH}$ 7.8) (buffer 1).

Nine other trypanosomatids, previously described as belonging to the genus Phytomonas according to various criteria, were cultured in a similar way. The Phytomonas isolates were from: mango (Mangifera indica), clover (Trifolium sp.) and tomato (Lycopersicon esculentum), all from Spain [2]; from latex plant E. pinea (EpiM1) [11]; from the phloem of coconut palm (Hart1) [1]; from the insects Veneza zonata (Coreidae, 40/460, TCC-203) and Fabrictilis gonagra (Coreidae, 19/231G41, TCC110 ); and from Brazilian tomato isolates (P. serpens and 10T) [12].

Similarly, two species from the genus Herpetomonas (H. samuelpessoai, ATCC 30252; H. davidi, TCC 048) were grown, as was one species from the genus Crithidia (C. luciliae, ATCC 14765) and another from the genus Leptomonas (L. collosoma, ATCC30261). Three strains of the genus Trypanosoma (T. cruzi, maracay strain); an isolate from an asymptomatic case in Brazil and another isolate from Peru [13], and Leishmania (L. donovani, LCR-L133).

\subsection{Antigen preparations}

The cells were suspended $(0.5-0.6 \mathrm{~g}$ wet $\mathrm{w} / \mathrm{v})$ in 3 $\mathrm{ml}$ of buffer1, and disrupted by three cycles of sonic disintegration, $30 \mathrm{~s}$ each to $60 \mathrm{~V}$. The sonicated homogenate was centrifuged at $1500 \mathrm{~g}$ for $5 \mathrm{~min}$ at $4{ }^{\circ} \mathrm{C}$, and the pellet was washed three times with buffer 1 , for a total supernatant fraction of $9 \mathrm{ml}$. This fraction was centrifuged $\left(2500 \mathrm{~g}\right.$ for $10 \mathrm{~min}$ at $\left.4{ }^{\circ} \mathrm{C}\right)$, the supernatant collected, and solid ammonium sulphate added. The protein fraction, which precipitated between $30 \%$ and $85 \%$ salt concentration, was centrifuged $\left(9000 \mathrm{~g}\right.$ for $20 \mathrm{~min}$ at $4{ }^{\circ} \mathrm{C}$ ), redissolved in $2.5 \mathrm{ml}$ of $20 \mathrm{mM}$ potassium phosphate buffer, $\mathrm{pH} 7.8$ containing $1 \mathrm{mM}$ EDTA (buffer 2) and dialysed in a Sephadex G-25 column (Pharmacia, PD 10), previously balanced with buffer 2 , bringing it to a final volume of $3.5 \mathrm{ml}$ (antigen fraction).

\subsection{Polyclonal serum}

To obtain the specific antibodies against the SODII [10], we immunized two female 4-week-old Balb-C mice (concentration of proteins of $2 \mathrm{mg} / \mathrm{ml}$ ) were separated by electrophoresis of IEF 3-9 in polyacrylamide gels [10]. Afterwards, the lane corresponding to the first well was cut and the SOD activity revealed [14]. From the remaining gel the zones corresponding to the activity bands of SODII ( $\mathrm{pI}$ : 3.6) were cut, ground and homogenized with sterile buffer phosphate (PBS). The mice were then each injected intraperitoneally in four immunizations, the first with complete Freund's adjuvant (CFA) and the following three (booster immunizations) with incomplete Fruend's adjuvant (IFA) at 10-day intervals. The sera were collected 15 days after the last booster immunization by cardiac puncture, following the method described in Current Protocols. In the case of SODI, the same procedure was followed to obtain the anti-SODI serum. In addition, the serum from the mouse that had not been immunized with the antigen fraction (control serum) was collected. 


\subsection{Western blot analysis}

The antigen fraction from $P$. characias were run on IEF 3-9 gels (concentration of proteins of $2 \mathrm{mg} / \mathrm{ml}$ ), and afterwards transferred to nitrocellulose, for $30 \mathrm{~min}$, as described the Phast-System manual. The membrane was blocked for $2 \mathrm{~h}$ at room temperature using $0.4 \%$ gelatine and $0.2 \%$ Tween 20 in PBS, followed by three washes in $0.1 \%$ Tween 20 in PBS (PBS-T), and incubated for $2 \mathrm{~h}$ at room temperature, on the one hand, with negative serum and anti-SODI serum at a dilution of $1 / 100$. And on the other hand with anti-SODII serum at dilutions of: $1 /$ $50,1 / 100,1 / 250,1 / 500,1 / 1000,1 / 2000,1 / 3000,1 / 5000,1 /$ $10,000,1 / 15,000,1 / 20,000$ and $1 / 40,000$. Before being washed and further incubated for $2 \mathrm{~h}$ at room temperature with the second antibody, anti-mouse $\operatorname{IgG}(\mathrm{Fc}$ specific) peroxidase conjugate $\left(\right.$ Sigma $\left.^{\circledR}\right)$ (dilution 1/ 1000). After washing as above, the substrate diam-

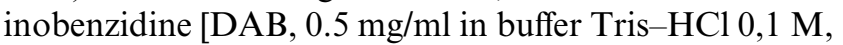
$\mathrm{pH} 7.4$, containing $\left.1 / 5000 \mathrm{H}_{2} \mathrm{O}_{2}(10 \mathrm{v} / \mathrm{v})\right]$ was added and the reaction stopped with several washes in distilled water.

The anti-SODII serum was assayed in the same way, against the antigen fractions obtained from the other cultured protozoa belonging to different genera. The dilution of the anti-SODII serum was in all cases $1 / 500$, except for $C$. luciliae and $L$. collosoma, which was assayed at a dilution of $1 / 500$ and $1 / 1000$.

\subsection{Immunofluorescence microscopy}

Cells were harvested by centrifugation, washed three times and resuspended in PBS, and settled on the coverwell for immunofluorescence until the evaporation of the buffer. Afterwards, the cells were fixed with acetone at room temperature. The immunofluorescence staining was then performed: the cells were first incubated with the anti-SODII serum and another cells with the control serum, for $30 \mathrm{~min}$ at room temperature (dilution 1/100). The coverwell was washed three times in PBS, and incubated $30 \mathrm{~min}$ at room temperature with the secondary antibody: antimouse IgG (Fab specific) conjugated with FITC $\left(\right.$ Sigma $\left.^{\circledR}\right)$ at a dilution of $1 / 100$ in PBS and with Evans blue $(0.003 \%)$. Next, the coverwell was washed and the coverslips put in place with PBS-buffered glycerine ( 9 vol. of glycerine, 1 vol. of PBS) for examination under an Olympus BH-2 fluorescence microscope.

\subsection{Immunocytochemistry}

The cells were harvested by centrifugation and washed three times in PBS, and fixed with $2.5 \%$ glutaraldehyde in cacodylate buffer, $\mathrm{pH} 7.0$ for $12 \mathrm{~h}$ at $4{ }^{\circ} \mathrm{C}$. Afterwards, the button was washed three times with carbonate buffer, $\mathrm{pH}$ 9.0, and treated with LR White resin to make the grid.

For the blocking of the non-specific sites, the grids were incubated with a solution of $0.5 \%$ albumin $(\mathrm{w} / \mathrm{v})$ in PBS- $0.05 \%$ Tween 20 and then incubated with the antiSODII mouse serum for $30 \mathrm{~min}$ at room temperature at the dilutions $1 / 50$ and $1 / 100$ in PBS. After another washing with PBS, the grids were incubated with the colloidal-gold-labelled complex Protein A-10 nm $\left(\right.$ Sigma $\left.^{\circledR}\right)$ at a dilution of $1 / 25$ in PBS with $0.5 \%$ albumin $(\mathrm{w} / \mathrm{v})$ and $0.5 \%$ Tween 20 , for $30 \mathrm{~min}$ at room temperature. Again, the samples were washed with PBS and distilled water and examined by transmission electron microscopy. Simultaneously, a control was tested by incubation directly with the protein A, without prior incubation with serum.

\section{7. $N$-terminal peptide sequencing}

The automated amino-acid sequencing (Applied Biosystems model 477A instruments) of the purified SODII was performed directly from PVDF membranes (Immobilion-P polyvinylidene difluoride membrane; Millipore) by Bryan Dunbar (Department of Molecular and Cell Biology, University of Aberdeen, Aberdeen, Scotland, UK). Double-cleavage and double-extraction programs were used to maximize cleavage at each cycle. Each instrument was equipped with on-line PTH analysis and used either gas-phase delivery, with the manufacturer's standard 50-min program, or pulsed-liquid delivery, using a novel "FASTBLOT" program of 27-min duration, which had been designed in house [15].

\section{Results}

\subsection{Immunogenicity of the SODs}

Fig. 1 reflects the Western blot of the anti-SOD sera. Both in the case of the control serum and the anti-SODI serum (lanes 1 and 2), the reaction was negative at a dilution of $1 / 100$. Meanwhile, in the case of the antiSODII serum (lanes 3-14), the reactions proved positive at dilutions from $1 / 50$ to $1 / 40,000$.

The anti-SODII serum at a dilution of $1 / 500$, was assayed by Western blot against the antigen fractions of different protozoan parasites for which the isoenzymatic profile was already known [10]. The result of the assay is shown in Fig. 2, indicating that only the isolates considered to belong to the genus Phytomonas presented a positive reaction (lanes $1-9$ and lane 12). However, the antigen fractions of C. luciliae (lane 17) and L. collosoma (lane 18) also showed a positive reaction to a dilution of 


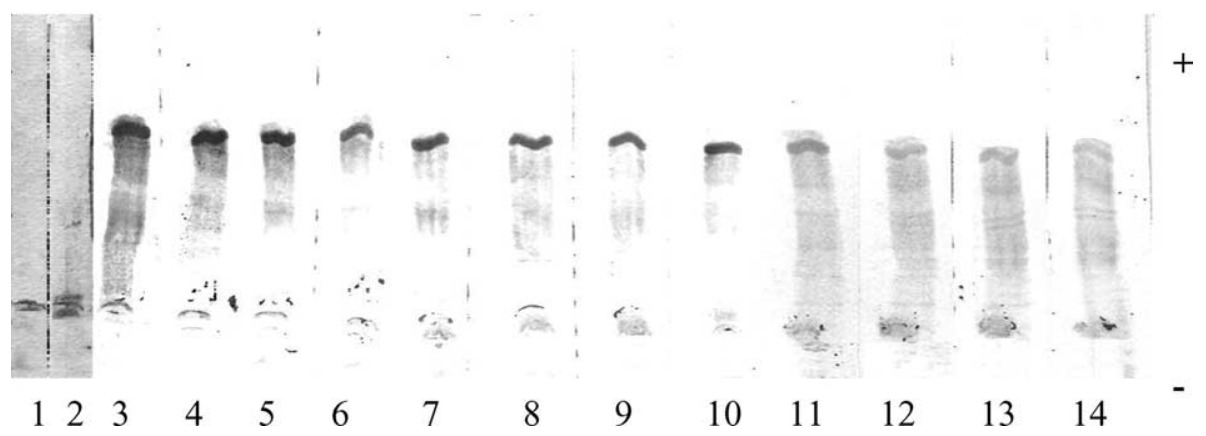

Fig. 1. Detection of the SOD by Western blot of the polyclonal serum: anti-SODI and anti-SODII (1) Control serum - dilution 1/100. (2) Serum antiSODI - dilution 1/100. (3-14) Serum anti-SODII, dilutions: (3) 1/50, (4) 1/100, (5) 1/250, (6) 1/500, (7) 1/1000, (8) 1/2000, (9) 1/3000, (10) 1/5000, (11) $1 / 10,000$, (12) $1 / 15,000,(13) 1 / 20,000$ and (14) $1 / 40,000$.

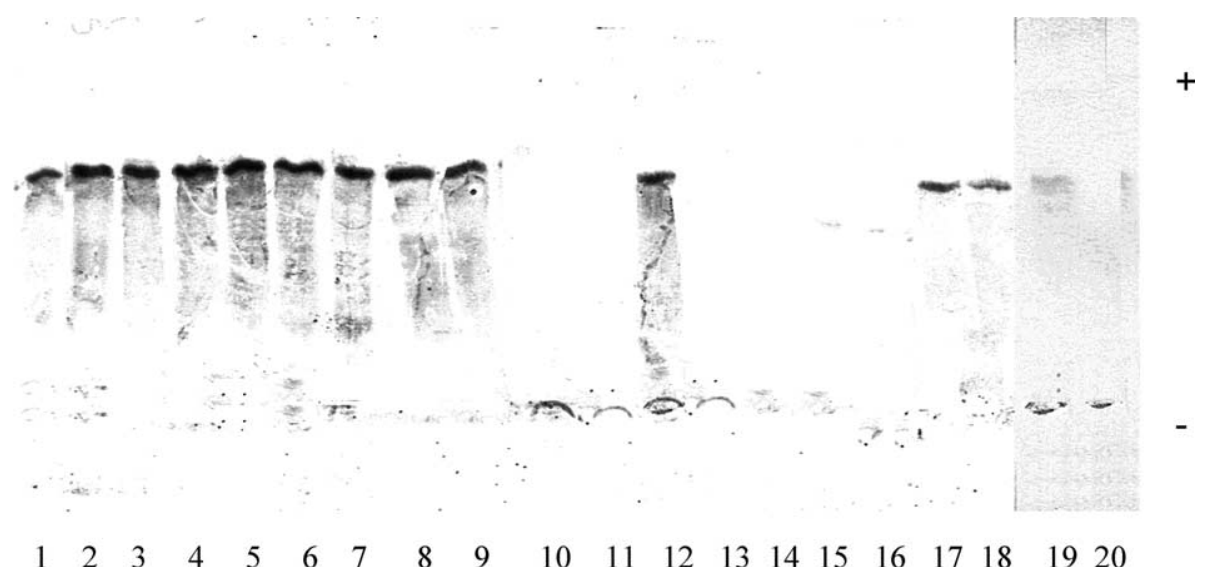

Fig. 2. Western blot with anti-SODII serum (1-18) dilution 1/500 and (19-20) 1/1000. (1) Phytomonas hartrot, (2) Phytomonas isolated from E. pinea; (3) Phytomonas isolated from E. characias, (4) Phytomonas isolated from Trifolium sp., (5) Phytomonas serpens, (6) Phytomonas isolated from Lycopersicon esculentum from Brazil, (7) Phytomonas isolated from L. esculentum from Spain, (8) Phytomonas isolated from Fabrictilis gonagra; (9) Phytomonas isolated from Veneza zonata; (10) Herpetomonas samuelpessoai, (11) Herpetomonas davidi, (12) Phytomonas isolated from Mangifera indica, (13) Trypanosoma cruzi strain maracay, (14) Trypanosoma isolated from human from Brazil, (15) Trypanosoma cruzi isolated from Peru, (16) Leishmania donovani, (17 and 19) Crithidia luciliae, (18 and 20) Leptomonas collosoma.

$1 / 500$, but not to a greater dilution of the serum $(1 / 1000)$ (lanes 19 and 20).

\subsection{Location of SODII}

The subcellular distribution of SODII, was estimated by immunofluorescence (IFI) and immunocytochemistry. With the indirect immunofluorescence (Fig. 3B), the cells presented uniform fluorescence for the entire surface of the parasite against the anti-SODII serum. While the reaction of the control serum were negative (Fig. 3A).

The subcellular location of the SODII in the grids of $P$. characias, for the complexes formed by the colloidal-gold anti-SODII-protein antibody are shown in Fig. 4. These complexes were found distributed more or less uniformly, although with somewhat greater concentration in the nucleus, nucleolus, glycosomes, and membranes.
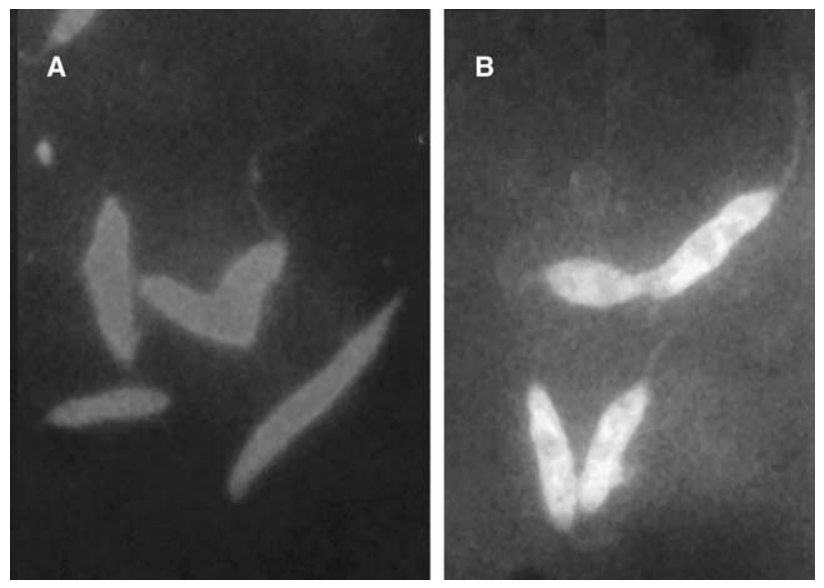

Fig. 3. IFI of Phytomonas isolated from E. characias. (A) negative control, Phytomonas incubated with control serum; (B) positive reaction, Phytomonas incubated with anti-SODII serum. 

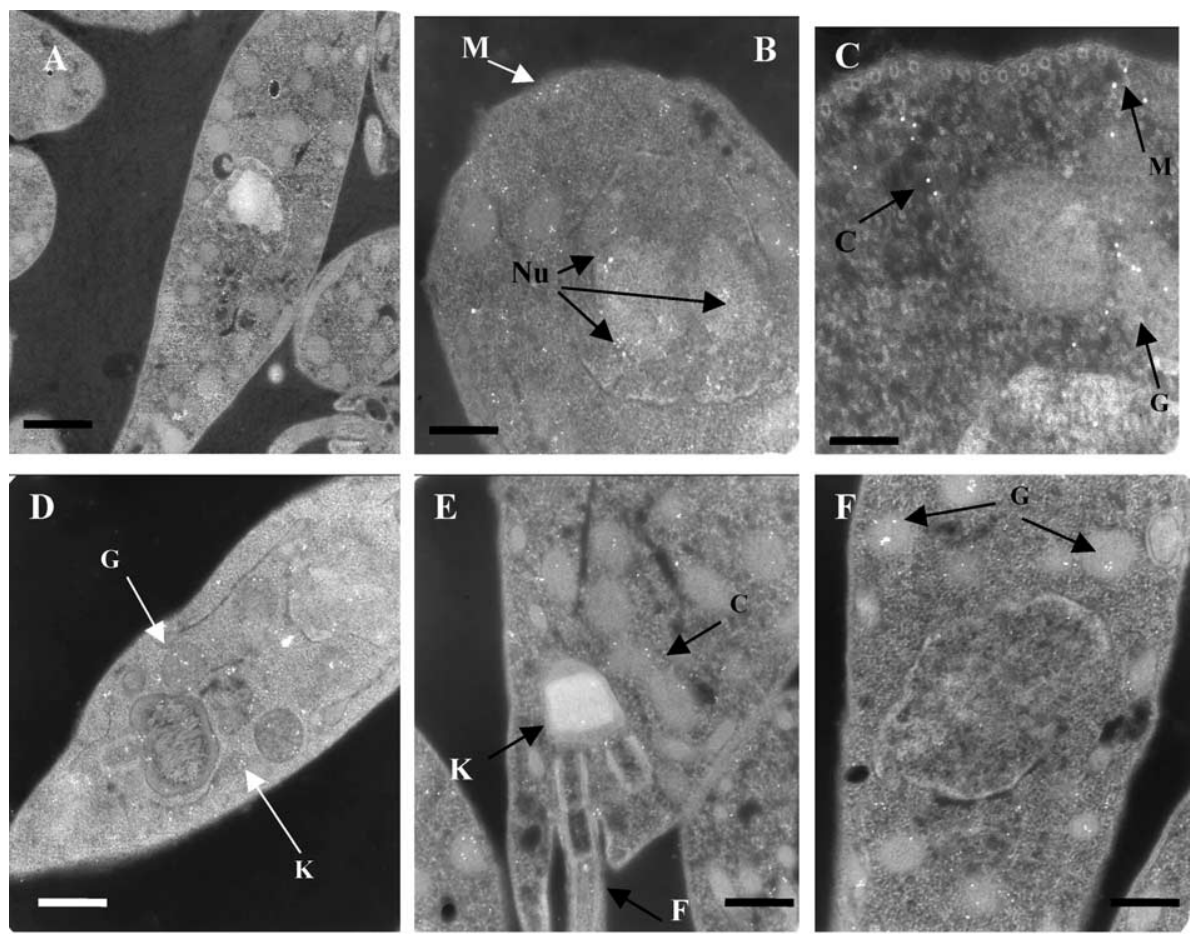

Fig. 4. Immunocytochemistry under the transmission electron microscope. (A) Control (bar $=0.583 \mu \mathrm{m}$ ). (B-D) Antibody-protein complex A (dilution 1/50): $(\mathrm{B}-\mathrm{bar}=0.233 \mu \mathrm{m}) ;(\mathrm{C}-\mathrm{bar}=0.082 \mu \mathrm{m})$; and $(\mathrm{D}-\mathrm{bar}=0.233 \mu \mathrm{m})$. Antibody-protein complex A (dilution 1/100): $(\mathrm{E}$ and $\mathrm{F}-$ bar $=0.233 \mu \mathrm{m})$.

\subsection{N-terminal sequencing of the SODII}

Approximately, $1 \mu \mathrm{g}$ of the purified SODII was subjected to SDS-PAGE and subsequently electroblotted to a PDVF membrane. The $22-\mathrm{kDa}$ protein visualized by Coomassie staining was cut out and sequenced by Edman degradation, which unequivocally identified the first 15 amino acids (MPFAAAELPYATDALA).

\section{Discussion}

Previously, we had purified and biochemically characterized two isoenzymes (SODI and SODII) from Phytomonas isolated from E. characias. It is known that in other parasitic protozoa, the enzyme SOD behaves as an immunogenic protein [7], and therefore the aim of the present work was to study the immunogenic properties of this important enzyme. With this aim, we obtained a polyclonal SODI and SODII serum. The anti-SODI serum, by Western blot, showed a negative reaction against the antigen fraction, while the anti-SODII reacted positively (up to a dilution of $1 / 40,000$ ). This unexpected result indicates that SODII is a highly immunogenic protein and opens the possibility of its use as a diagnostic tool.

The enormous heterogeneity of species belonging to the family Trypanosomatidae hampers taxonomic classification, which is fundamental for the study of the epidemiology of the diseases. The traditional methods for including a given isolate within a genus (morphometry, parasitemia curves, pathogenicity, geographic distribution, tissue location, host) are insufficient [1]. This has led to the search for other methods or molecular markers with the aim of proper characterization of these isolates [13]. For these reasons, we here investigate the possibility that the immunogenic property that we had determined in the SODII could be applicable to the identification of species. In this study, we included 17 trypanosomatids considered to belong to different Trypanosomatidae genera. The reaction of the anti-SODII serum against the antigen fractions of each of these trypanosomatids was different. That is, the isolates considered to belong to the genus Phytomonas reacted positively to a dilution greater than $1 / 1000$, a requisite more than satisfied by this serum, as its positivity reached up to $1 / 40,000$, with a negative serum reaction against the antigen fractions of the species $T$. cruzi, $L$. donovani, $H$. samuelpessoai, $H$. davidi, $C$. luciliae and $L$. collosoma. This demonstrates that SODII is useful for identifying species belonging to Phytomonas.

By IFI, SODII appeared uniformly distributed over the entire cell surface, and by immunocytochemistry its distribution was detected in the cell interior, concentrated primarily in the nucleus, glycosomes, and membranes. These data confirm our earlier study [10], a digitonin-tritation experiment in which the SOD activity showed a bimodal activation curve where $65 \%$ of the 
activity concentrated in the cytosol fraction, $15 \%$ in the glycosomes, and the rest (20\%) failed to solubilize even at the highest digitonin concentration, indicating that part of the SOD could be associated with membranes. Therefore, SODII would be formed in the cytosol and afterwards transported to the glycosomes, as occurs with other glycosomal enzymes [16], and to the membranes, and part of this enzyme could even be secreted to the exterior by the parasite, according to the preliminary data recently gathered in our laboratory.

In addition, the alignment of the $\mathrm{N}$-terminal sequence of the SODII bears similarities with other sequences of other protozoa (data not shown) but it becomes necessary to sequence the complete gene of the enzyme. Nevertheless, with the sequencing of the N-terminal of the protein, we can design primers that enable us to decipher the entire sequence of the gene of SODII by PCR assay.

All this confirms that the enzyme superoxide dismutase could be a molecular tool to identify the members of the genus Phytomonas. For its immunogenic characteristics and its location for the diagnosis, not only for the genus Phytomonas, but that it could be extrapolated to other trypanosomatids of importance for animal and human health since $P$. characias can be considered a metabolic model for the study of trypanosomatids. In addition, SOD for its metabolic importance and its crucial role in the defence of parasites against host attack, is a potential chemotherapeutical target for the design of drugs directed at the control of diseases produced by different trypanosomatids.

\section{Acknowledgements}

This work was supported by "ATP 2002/30: Circulation of Trypanosomatidae" CIRAD (FRANCE) project.

\section{References}

[1] Dollet, M. (1984) Plant trypanosomes case study. In: Identification and Characterization of Pest Organism (Hawksworth, D.L., Ed.), pp. 415-426. CAB International.

[2] Sánchez-Moreno, M., Fernández-Becerra, C., Mascaró, C., Rosales, M.J., Dollet, M. and Osuna, A. (1995) Isolation, in vitro culture, ultrastructure study, and characterization by lectinagglutination test of Phytomonas isolated from tomatoes (Lycopersicum esculentum) and cherimoyas (Annona cherimolia) in southeastern Spain. Parasitol. Res. 81, 575-581.
[3] Podlipaev, S. (2001) The more insect trypanosomatids under study - the more diverse Trypanosomatidae appears. Int. J. Parasitol. 31, 648-652.

[4] Ahmed, H., Schott, E.J., Gauthier, J.D. and Vasta, G.R. (2003) Superoxide dismutase from the oyster parasite Perkinsus marinus: purification, biochemical characterization, and development of a plate microassay for activity. Anal. Biochem. 318, 132-141.

[5] Bannister, J.V., Bannister, W.H. and Rottilio, G. (1987) Aspects of the structure, function and application of superoxide dismutases. Crit. Rev. Biochem. 22, 111-180.

[6] Paramchuck, W.J., Ismail, S.O., Bhatia, A. and Gedamu, L. (1997) Cloning, characterization and overexpression of two iron superoxide dismutase cDNAs from Leishmania chagasi: role in pathogenesis. Mol. Biochem. Parasitol. 90, 203-221.

[7] Pérez-Fuentes, R., Guégan, J.F., Barnabé, C., López-Colombo, A., Salgado-Rosas, H., Torres-Rasgado, E., Briones, B., RomeroDiaz, M., Ramos-Jiménez, J. and Sánchez-Guillén, M.C. (2003) Severtity of chronic Chagas disease is associated with citokine/ antioxidant imbalance in chronically infected individuals. Int. J. Parasitol. 33, 293-299.

[8] Kabiri, M. and Steverding, D. (2001) Identification of a developmentally regulated iron superoxide dismutase of Trypanosome brucei. J. Biochem. 360, 173-177.

[9] Quesada, J.M., Entrala, E., Fernández-Ramos, C., Marín, C. and Sánchez-Moreno, M. (2001) Phytomonas spp.: superoxide dismutase in plant trypanosomes. Mol. Biochem. Parasitol. 115, 123127.

[10] Marín, C., Rodriguez-Gonzalez, I., Hitos, A., Rosales, M.J., Dollet, M. and Sánchez-Moreno, M. (2004) Purification and characterization of two iron superoxide dismutase of Phytomonas sp. isolated from Euphorbia characias (Plant Trypanosomatids). Parasitology, in press.

[11] Guerrini, F., Ségur, C., Gargani, D., Tibayrenc, M. and Dollet, M. (1992) An isoenzyme analysis of the genus Phytomonas: genetic, taxonomic and epidemiologic significance. J. Protozool. 39, 516-521.

[12] Fernández-Becerra, C., Osuna, A., Muller, E., Dollet, M. and Sánchez-Moreno, M. (1996) Characterization of isolated from fruits by electrophoretic isoenzymes and kinetoplast-DNA analysis. FEMS Microbiol. Lett. 145, 463-468.

[13] Miralles, D., Marín, C., Magán, R., Fernández-Ramos, C., Entrala, E., Cordova, O., Vargas, F. and Sánchez-Moreno, M. (2002) In vitro culture and biochemical characterization of six trypanosome isolates from Peru and Brazil. Exp. Parasitol. 102, 23-29.

[14] Beyer, W.F. and Fridovich, I. (1987) Assaying for superoxide dismutase activity: some large consequences of minor changes in conditions. Anal. Biochem. 161, 559-566.

[15] Deka, R.K., Anton, I.A., Dunbar, B. and Coggins, J.R. (1994) The characterisation of the shikimate pathway enzyme dehydroquinase from Pisum sativum. FEBS Lett. 349, 397402.

[16] Parson, M., Furuya, T., Pal, S. and Kessler, P. (2001) Biogenesis and function of peroxisomes and glycosomes. Mol. Biochem. Parasitol. 115, 19-28. 